\title{
Diacronie
}

Studi di Storia Contemporanea

$N^{\circ} 16,4 \mid 2013$

Le monarchie nell'età dei nazionalismi

\section{Emilio La Parra López (coord.), Imagen del poder. Reyes y regentes en la España del siglo XIX}

Daniel Galván Desvaux

\section{Q OpenEdition \\ 1 Journals}

\section{Edición electrónica}

URL: http://journals.openedition.org/diacronie/954

DOI: 10.4000/diacronie.954

ISSN: 2038-0925

\section{Editor}

Association culturelle Diacronie

Referencia electrónica

Daniel Galván Desvaux, «Emilio La Parra López (coord.), Imagen del poder. Reyes y regentes en la España del siglo XIX», Diacronie [En línea], Nº16, 4 | 2013, documento 12, Puesto en línea el 01 diciembre 2013, consultado el 23 septiembre 2020. URL : http://journals.openedition.org/diacronie/ 954 ; DOI : https://doi.org/10.4000/diacronie.954 


\section{RESEÑN:}

\section{Emilio LA PARRA LÓPEZ (coord.), Imagen del poder. Reyes y regentes en la España del siglo XIX, Madrid, Síntesis, 2011, 472 pp.} por Daniel GALVÁN DESVAUX*

A lo largo de la historia, las instituciones y personas que han ostentado el poder han necesitado ofrecer una imagen adecuada de sí mismos; una imagen que les permitiese consolidar su posición y legitimar el uso que hacían de ese poder. En el caso del siglo XIX español, esta situación estuvo marcada por la necesidad de la monarquía, como institución, y de los reyes y regentes, como depositarios del poder monárquico, de ofrecer una imagen que permitiese reforzar sus actuaciones.

Desde muy temprano, éste ha sido un tema de gran interés entre los historiadores, que han intentado comprender cómo se construía y transformaba la imagen del poder de los monarcas, hecho fundamental para entender la identidad de ese poder. La consecuencia lógica ha sido la publicación de diferentes obras sobre esta cuestión. Sin duda, una de las más destacas fue la de Ernst Kantorowicz sobre las representaciones que la teología política conformó de los reyes en la Edad Media. En esta misma línea ahondaron trabajos posteriores para el caso de la monarquía española, como el de Carmelo Lisón Tolosana para el período de los Austria o algunos otros sobre el siglo XVIII, pudiendo destacar los estudios de María de los Ángeles Pérez Samper sobre los primeros Borbones. Sin embargo, parecía necesario incidir en lo acontecido con los reyes y regentes durante el siglo XIX, en una época en la que se expandió el valor de la opinión pública.

De esta necesidad surge la obra conjunta Imagen del poder. Reyes y regentes en la España del siglo XIX, coordinada por Emilio La Parra López, cuyos autores se encuadran dentro del ámbito investigador de la Universidad de Alicante. Como 
muestran sus publicaciones ${ }^{1}$, todos ellos son verdaderos especialistas en el estudio de la imagen que la monarquía española desarrolló durante el siglo XIX.

En este caso, el análisis de los diferentes reinados y regencias se articula de una forma cronológica. El punto de partida es el tránsito entre el siglo XVIII y el XIX, explicado por el propio Emilio La Parra López a través de la figura de de Fernando VII (1808/1813-1833). La figura del rey estará marcada en los años de la Guerra de Independencia (1808-1814) por los discursos del príncipe inocente y del monarca deseado. Sin embargo, con la redacción de la Constitución de 1812, la imagen de la monarquía cambiará y se entenderá que Fernando VII era un rey constitucional elegido por las Cortes.

Tras el final de la guerra, el rey fue aclamado a su regreso, pero no creyó nunca en su nueva imagen y rompió con el ideario político liberal. El resultado fue que los liberales tuvieron que conformar la ilusión del rey engañado por sus colaboradores, para justificar la actuación del monarca. Durante el Trienio Liberal (1820-1823), se implantó de nuevo la simbología del rey constitucional, pero con la reposición de los modelos absolutistas durante la década de los años 30, la figura de Fernando VII se fue deteriorando hasta ser eminentemente negativa.

Frente a estos discursos sobre Fernando VII se creará la imagen de José I Bonaparte (1808-1813), analizada por Antonio J. Piqueres Díez. El nuevo monarca fue siempre consciente de la necesidad de legitimar su presencia en España a través de una representación determinada de su poder. Por ello, configuró la idea de una España en decadencia, necesitada de una regeneración que solo podía encarnar el nuevo rey. Aun así, el perfil que trascendió en la opinión pública de José I fue siempre profundamente peyorativo, debido a la comparación con su hermano Napoleón, frente al que aparecía como un actor secundario. Las imágenes más comunes de José I fueron la del monarca alcohólico y jugador, la del hombre físicamente detestable e iletrado o la del soberano lujurioso. Pero, entre otros sectores de la sociedad, también se desarrolló la del rey filósofo, francmasón y ateo. Como explica el profesor Piqueres Díez, parece que todo esto respondió a la necesidad de los dos bandos enfrentados durante la guerra de mitificar las figuras tanto de Fernando VII como del propio José I.

Al avanzar el siglo XIX, nos encontramos con una de las realidades más características de la monarquía española, el establecimiento de regencias por minorías de edad de los monarcas. Con la muerte de Fernando VII se inició un período de estas

\footnotetext{
1 Por señalar una de las más recientes, vid.: SEVILLANO CALERO, Francisco, SOLER PASCUAL, Emilio, Diarios de viaje de Fernando VII (1823 y 1827-1828), Alicante, Publicaciones de la Universidad de Alicante, 2013.
} 
características bajo dos figuras, primero la reina María Cristina de Borbón y después el general Espartero.

La imagen de María Cristina de Borbón (1833-1840) pasa por toda una serie de etapas, como demuestra María Ángeles Casado Sánchez, iniciándose con una visión positiva en torno a los años 30. Durante los primeros años de la regencia, la reina María Cristina se consolida, en el enfrentamiento con el carlismo, como una mujer llena de virtudes. Este perfil de la regente se irá deteriorando hasta los años 40, cuando María Cristina tendrá que abandonar la regencia en favor del general Espartero.

Sin embargo, los años de su exilio en Francia le sirven para potenciar la visión de la reina madre alejada de sus hijos y del trono. Por ello, tras la declaración de la mayoría de edad de Isabel II en 1844, la regente puede volver a España para representar ese papel. En estos años, se extienden las acusaciones de corrupción y codicia en torno a María Cristina, cuyo perfil se deteriora aún más por su matrimonio con su antiguo amante. Todo esto llevará a que la reina tenga que volver a salir de España en 1854, en pleno proceso revolucionario. Lo cierto es que su figura no se recuperará hasta finales del siglo XIX, durante la regencia de María Cristina de Habsburgo, con el objetivo de legitimar a la nueva regente.

Tras la deposición de la reina en 1840, el profesor Pedro Díaz Marín analiza las imágenes del poder generadas durante la regencia general Espartero (1840-1843). El perfil que se ofrece de Espartero es el de un pacificador, el del héroe popular capaz de solucionar todos los problemas de la sociedad española. La identificación entre la imagen de Espartero y los ideales del progresismo y de la nueva sociedad burguesa fue total. Frente a esta proyección, los seguidores de la anterior regente diseñarán la del usurpador de la autoridad monárquica cuyo gobierno era resultado de la revolución. Estas dos imágenes convivieron durante la regencia de Espartero, que tuvo que hacer frente a dos grandes problemas, el enfrentamiento con la Santa Sede por la cuestión religiosa y las relaciones exteriores con Francia. Ambos asuntos dañaron la percepción tenida de Espartero, que para 1842-1843 fue acusado de instaurar un sistema autoritario y contrario al sentimiento monárquico. El resultado fue el establecimiento de una visión del regente como un elemento que ponía en peligro la continuidad monárquica, por lo que se puso fin a su regencia en el verano de 1843.

Como consecuencia del final de la regencia de Espartero, se iniciará el reinado de Isabel II (1843-1868), en un momento crucial para la legitimación del poder monárquico, como analiza Rosa Ana Gutiérrez Lloret. Durante la época de las regencias, Isabel fue presentada por el liberalismo como la representante de la unidad nacional contra el absolutismo carlista. Pero, tras su ascenso al trono, se alteró esta 
idea por la de debilidad, debido a dos factores: la vida amorosa extramatrimonial de la reina, que contravenía el modelo de mujer de la nueva sociedad burguesa, y la religiosidad ferviente y caduca que ejercía la camarilla de religiosos y beatas de su entorno.

Esta situación culminó en la revolución de 1854, de la que la reina logró salir indemne identificándose con el modelo constitucional. Sin embargo, este movimiento sería un primer aviso para la Corona, puesto que durante la década de los 60 la imagen de la monarca se menoscabará por su excesiva vinculación con los moderados. Su descrédito sería total cuando se aireó su vida amorosa. De esta manera, la revolución de 1868 expulsará a la reina de España, que aparecerá identificada con la corrupción, el autoritarismo y con la indecencia pública y privada. Esta representación se mantendrá durante sus años en el exilio, si bien es cierto que con el paso del tiempo se irá mitigando, para dejar traslucir simplemente una visión negativa de su reinado.

La revolución de 1868 abre un nuevo período para la monarquía española, marcado por los profundos cambios en la forma de entender esta institución. El resultado fue el breve reinado de Amadeo I y su esposa María Victoria (1870-1873), que como expone Alicia Mira Abad, se entendió como una solución para cerrar los excesos revolucionarios y garantizar el mantenimiento de las instituciones liberales. El nuevo monarca nacido de la Constitución de 1869 se presentó como el garante de un sistema político constitucional y parlamentario, que representaría la unidad de una nación progresista.

En esta situación, se inserta la elección de Amadeo de Saboya, que siempre se mostró como un rey cercano al pueblo, justo y generoso, cuyo deseo fue identificar a la monarquía con los valores democráticos. Sin embargo, estos deseos del rey, su condición de extranjero o su imagen de excesiva cercanía fueron rebatidos desde ciertos sectores políticos. Por otra parte, Amadeo I y María Victoria supieron adscribirse a los valores familiares burgueses predominantes, con lo que lograron alejarse de la actuación de Isabel II. La reina fue presentada como el ejemplo burgués de mujer virtuosa, aunque parece que llevó a cabo una actividad política más importante de lo que se piensa tradicionalmente. A pesar de todas estas representaciones, parece que los monarcas no desearon la Corona bajo las circunstancias en las que esta se encontraba, lo cual derivó en su abdicación en 1873 y la instauración de la Primera República Española (1873-1874).

Con el final de la experiencia republicana, como señala Rafael Fernández Sirvent, se estableció una nueva imagen de la monarquía bajo la figura de Alfonso XII (18741885). Más allá de algunas caracterizaciones negativas de juventud, la conformación de 
la imagen de Alfonso XII será realizada por Antonio Cánovas del Castillo. Especialmente, el perfil del rey se detalla en el Manifiesto de Sandhurst, en el que aparece como un hombre maduro capaz de restaurar la unidad nacional bajo el constitucionalismo. La posible monarquía de Alfonso se expone como un elemento históricamente consustancial a España, pero adecuada a los nuevos tiempos.

Con el ascenso al trono de Alfonso XII, Cánovas genera la imagen del rey soldado, como una forma de controlar el papel del ejército en la vida política y de enfrentarse al carlismo, cuya derrota permitió presentar al rey como el pacificador de la nación. Ciertamente, la figura que se construyó de Alfonso XII fue eminentemente positiva para el pueblo, que siempre le sintió como un monarca cercano y fiel al modelo liberal. Frente a estas proyecciones, aparece la utilización de la censura durante gran parte de su reinado para refrenar cualquier crítica a la monarquía o a la religión católica. La temprana muerte del rey en 1885 dio paso a una etapa compleja, pero la persona de Alfonso XII se fue mitificando como la del rey constitucional y pacificador de España.

La muerte de Alfonso XII provocó el establecimiento de una nueva regencia ocupada por la reina María Cristina de Habsburgo (1885-1902), que, como expone Mónica Moreno Seco, intentó consolidar la institución monárquica en un momento de peligro y debilidad para la Corona. Los objetivos principales fueron mantener la continuidad dinástica, de ahí las comparaciones con la anterior regente María Cristina de Borbón, y conservar el sistema político de la Restauración. La creación de una imagen para la regente estuvo sujeta a su condición de mujer y a la creencia burguesa de que su ámbito de actuación era el privado y no el ejercicio del poder político. Esta idea permitió a la Corona y a la regente salir más o menos ilesos de la crisis colonial de 1898. Por ello, cuando finalizó su regencia en 1902, María Cristina fue presentada como una reina moderada y prudente, que sería vista en los últimos años de su vida como una anciana caritativa rodeada de su familia.

Como conclusión, podemos señalar que durante la última regencia del siglo XIX se consiguió consolidar la situación de la monarquía y permitir el acceso al trono de Alfonso XIII. A través de las diferentes visiones que se exponen en esta obra podemos intuir lo que sucederá a comienzos del siglo XX, a pesar de que los autores abordan solo parcialmente las consecuencias que este proceso tendrá durante el reinado de Alfonso XIII. Por ello, nos gustaría destacar que en ese momento se comprendió que los intentos de la monarquía por identificarse con la nación española, solo habían sido una fórmula para potenciar sus intereses y legitimar su poder. Al menos esta es la idea que parece traslucir de las palabras de Ortega y Gasset en 1921, fecha de publicación de su 
España invertebrada: "Monarquía e Iglesia se han obstinado en hacer adoptar sus destinos propios como los verdaderamente nacionales; [...]"2.

En definitiva, este trabajo de conjunto nos permite conocer de una forma coherente la realidad política, pero también social y cultural de la España del siglo XIX. Pero, sobre todo, tiene una virtud más trascendental, la de completar un cierto vacío historiográfico sobre las representaciones mentales del poder monárquico en este tumultuoso siglo. Por tanto, nos encontramos ante una obra de referencia para comprender mejor la realidad de la monarquía española y su legitimación durante el siglo XIX, pero que también nos aporta algunas de las claves para atisbar la situación por la que la monarquía transitará durante en el siglo XX.

2 ORTEGA Y GASSET, José, España invertebrada: bosquejos de algunos pensamientos históricos, Madrid, Alianza, 1983, p. 49. Sobre las opiniones de Ortega y Gasset a cerca de la monarquía se puede consultar su artículo «El error Berenguer»publicado el 15 de noviembre de 1930 en el periódico «El Sol», conocido por su frase final Delenda est Monarchia. 


\section{* El autor}

Daniel Galván Desvaux es beneficiario del programa de Becas FPU del Ministerio de Educación, Cultura y Deporte. Realiza su tesis doctoral en la Universidad de Valladolid bajo la dirección del Dr. Antonio Cabeza Rodríguez. Desarrolla su línea de investigación en torno a la evolución de la monarquía española durante el Antiguo Régimen, sobre todo respecto al siglo XVII.

URL: < http://www.studistorici.com/progett/autori/\#GalvanDesvaux >

\section{Per citare questo articolo:}

GÁLVAN DESVAUX, Daniel, «Reseña: Emilio LA PARRA LÓPEZ (coord.), Imagen del poder. Reyes y regentes en la España del siglo XIX, Madrid, Síntesis, 2011, 472 pp.», Diacronie. Studi di Storia Contemporanea : Le monarchie nell'età dei nazionalismi, 29/12/2013,

URL: < http://www.studistorici.com/2013/12/29/galvan_desvaux_numero_16/ >

\section{Diacronie Studi di Storia Contemporanea $\beta$ www.diacronie.it}

Risorsa digitale indipendente a carattere storiografico. Uscita trimestrale.

redazione.diacronie@hotmail.it

Comitato di redazione: Marco Abram - Jacopo Bassi - Luca Bufarale - Alessandro Cattunar - Elisa Grandi - Deborah Paci - Fausto Pietrancosta - Matteo Tomasoni - Luca Zuccolo

Diritti: gli articoli di Diacronie. Studi di Storia Contemporanea sono pubblicati sotto licenza Creative Commons 2.5 Possono essere riprodotti a patto di non modificarne i contenuti e di non usarli per fini commerciali. La citazione di estratti è comunque sempre autorizzata, nei limiti previsti dalla legge. 